Epidemiology and Infection

cambridge.org/hyg

\section{Original Paper}

Cite this article: Bennett NJ, Imam N, Ingram RJ, James RS, Buising KL, Bull AL, Chen CS, Thursky KA, Worth LJ (2019). Skin and soft tissue infections and current antimicrobial prescribing practices in Australian aged care residents. Epidemiology and Infection 147, e87, 1-5. https://doi.org/10.1017/ S0950268819000128

Revised: 8 January 2019

Accepted: 15 January 2019

Key words:

Aged care; antimicrobial drugs; skin infections; surveillance system

Author for correspondence:

N. J. Bennett,

E-mail: Noleen.Bennett@mh.org.au

\title{
Skin and soft tissue infections and current antimicrobial prescribing practices in Australian aged care residents
}

Received: 29 August 2018

N. J. Bennett ${ }^{1,2}$, N. Imam², R. J. Ingram¹, R. S. James ${ }^{1}$, K. L. Buising ${ }^{1}$, A. L. Bull2, C. S. Chen ${ }^{1}$, K. A. Thursky ${ }^{1}$ and L. J. Worth ${ }^{2,3}$

${ }^{1}$ National Centre for Antimicrobial Stewardship, 792 Elizabeth St, Melbourne, Vic. 3000, Australia; ${ }^{2}$ Victorian Healthcare Associated Infection Surveillance System Co-ordinating Centre, 792 Elizabeth St, Melbourne, Vic. 3000, Australia and ${ }^{3}$ Department of Medicine, The University of Melbourne, Parkville, Vic. 3010, Australia

\begin{abstract}
To determine the burden of skin and soft tissue infections (SSTI), the nature of antimicrobial prescribing and factors contributing to inappropriate prescribing for SSTIs in Australian aged care facilities, SSTI and antimicrobial prescribing data were collected via a standardised national survey. The proportion of residents prescribed $\geqslant 1$ antimicrobial for presumed SSTI and the proportion whose infections met McGeer et al. surveillance definitions were determined. Antimicrobial choice was compared to national prescribing guidelines and prescription duration analysed using a negative binomial mixed-effects regression model. Of 12319 surveyed residents, $452(3.7 \%)$ were prescribed an antimicrobial for a SSTI and $29 \%$ of these residents had confirmed infection. Topical clotrimazole was most frequently prescribed, often for unspecified indications. Where an indication was documented, antimicrobial choice was generally aligned with recommendations. Duration of prescribing (in days) was associated with use of an agent for prophylaxis (rate ratio (RR) 1.63, 95\% confidence interval (CI) 1.08-2.52), PRN orders (RR 2.10, 95\% CI 1.42-3.11) and prescription of a topical agent (RR 1.47, 95\% CI 1.08-2.02), while documentation of a review or stop date was associated with reduced duration of prescribing (RR 0.33, 95\% CI 0.25-0.43). Antimicrobial prescribing for SSTI is frequent in aged care facilities in Australia. Methods to enhance appropriate prescribing, including clinician documentation, are required.
\end{abstract}

\section{Introduction}

In Australia, approximately 2670 aged-care homes (ACHs) provide resident accommodation and support, including assistance with day-to-day living and intensive forms of care. Almost 180 multi-purpose services (MPSs) also deliver a flexible mix of acute, sub-acute and aged care services to best meet a community's needs [1].

In these facilities, elderly populations are at increased risk for skin and soft tissue infections (SSTIs) [2] related to physiological, aged-related changes to the skin, decline in immune function and the presence of comorbid conditions such as vascular disease [3,4]. It is important that antimicrobial therapy for SSTIs is targeted and appropriately prescribed, in order to improve clinical outcomes and reduce risks of adverse outcomes (e.g. Clostridium difficile infection) and development of antimicrobial resistance associated with improper or prolonged use $[5,6]$.

Since 2015, all Australian aged care facilities (ACHs and MPSs) have been invited annually to participate in the Aged Care National Antimicrobial Prescribing Survey (acNAPS). This structured point-prevalence survey enables prevalence of infections and antimicrobial prescribing for all residents in these facilities who are present on the survey day to be estimated. Findings to date have identified SSTIs as the second most common infection among residents [7].

The objectives of this study were to: (i) determine the relative burden of specific SSTIs, (ii) estimate the prevalence and nature of antimicrobial prescribing for SSTIs and (iii) evaluate factors contributing to inappropriate prescribing of antimicrobial agents for SSTIs in Australian aged care facilities participating in the acNAPS. \section{article, distributed under the terms of the}

The Author(s) 2019. This is an Open Access Creative Commons Attribution licence (http:// creativecommons.org/licenses/by/4.0/), which permits unrestricted re-use, distribution, and reproduction in any medium, provided the original work is properly cited.

\section{CAMBRIDGE} UNIVERSITY PRESS

\section{Methods}

\section{Survey methodology}

Point-prevalence surveys of infections and antimicrobial use were completed by nurses, infection control professionals or pharmacists at participating facilities on a single survey day between 19 June and 1 September 2017. All data were obtained by review of residents' records (medical, nursing and medication charts). 
Data collected about antimicrobials prescribed on the survey day included clinical indication (reason for commencing an antimicrobial agent), rationale (i.e. prophylaxis $v s$. therapeutic), route, frequency and duration (start and review/stop dates). If not documented, the clinical indication for commencing the antimicrobial was interpreted by the surveyor based on other information available in the clinical records. If the antimicrobial start date was known and $<6$ months prior to the survey day, any documented infection signs and/or symptoms on the antimicrobial start date or 6 days prior were reported.

Prior to the survey day, education regarding the surveillance methodology was provided. Surveyors could participate in training webinars and a detailed user manual could be accessed via the National Antimicrobial Prescribing Survey (NAPS) website. Individual support was available by telephone or email liaison with the NAPS staff. Surveys were submitted on-line via a secure web portal.

\section{Definitions}

Evaluable SSTI clinical indications for prescribing antimicrobials were mapped to McGeer et al. standardised and accepted surveillance definitions [8] and included: cellulitis, soft tissue and wound infection; fungal skin infection; herpesvirus skin infection; and scabies. In accordance with the McGeer 'skin, soft tissue and mucosal infection' definition, conjunctivitis and oral candidiasis were also included. If infection signs and/or symptoms were reported, 'possible' infections were defined as those where at least one element of McGeer et al. criteria was reported. 'Confirmed' infections were defined as those that met all elements required for McGeer et al. criteria (Table 1).

Antimicrobial prescriptions included all antibiotic, antiviral, antifungal and anti-parasitic agents. The prevalence of antimicrobial prescribing for SSTI was defined as the proportion of all residents that were prescribed at least one antimicrobial for a SSTI clinical indication on the survey day.

\section{Data analysis}

The prevalence of residents prescribed $\geqslant 1$ antimicrobial for all clinical indications and the subset of indications specifically related to SSTI were calculated. For residents prescribed at least one antimicrobial where the known start date was $<6$ months prior to the survey day, the proportion of those with at least one infection sign and/or symptom and those with a McGeer et al. confirmed infection was also determined.

The frequency of specific antimicrobial agents for each SSTI clinical indication was calculated. Additionally, and as a measure of appropriateness, the prescribed agents were compared to the choice and route of antimicrobials recommended in national prescribing guidelines $[9,10]$ for mild early cellulitis or wound infection, cutaneous candidiasis, conjunctivitis, oral candidiasis, herpes simplex infections and scabies (including crusted scabies) (Supplementary Appendix I). This analysis was stratified according to route (oral or topical).

For prescriptions with known start dates $<6$ months prior to the survey day, duration of prescription (in days) was analysed using mixed-effects regression models. With a Poisson distribution for the dependent variable, significant over-dispersion was seen (sum of squared Pearson residuals vs. residual degrees of freedom, $P<0.01$ ); test for zero-inflation was insignificant
Table 1. Definitions for infections in surveyed aged care residents (McGeer et al. [1])

\begin{tabular}{|c|c|c|c|}
\hline No. & Infection & $\begin{array}{l}\text { Confirmed } \\
\text { infection }\end{array}$ & Criterion \\
\hline A & $\begin{array}{l}\text { Cellulitis/soft } \\
\text { tissue/wound }\end{array}$ & $\begin{array}{l}\text { At least one } \\
\text { criterion }\end{array}$ & $\begin{array}{l}\text { 1. Pus present at wound } \\
\text { skin or soft tissue site } \\
\text { 2. At least four sub-criteria } \\
\text { - Heat } \\
\text { - Redness } \\
\text { - Swelling } \\
\text { - Tenderness or pain } \\
\text { - Serous discharge } \\
\text { - One constitutional } \\
\text { criteria }^{\text {a }}\end{array}$ \\
\hline B & Conjunctivitis & $\begin{array}{l}\text { At least one } \\
\text { criterion }\end{array}$ & $\begin{array}{l}\text { 1. Pus from one or both } \\
\text { eyes present }>24 \mathrm{~h} \\
\text { 2. New or increased } \\
\text { conjunctival redness } \\
\text { 3. Itching or pain }>24 \mathrm{~h}\end{array}$ \\
\hline C & $\begin{array}{l}\text { Fungal skin } \\
\text { infection }\end{array}$ & $\begin{array}{l}\text { Criterion } 1 \\
\text { and } 2\end{array}$ & $\begin{array}{l}\text { 1. Characteristic rash or } \\
\text { lesions } \\
\text { 2. Doctor or laboratory } \\
\text { confirmation }\end{array}$ \\
\hline D & $\begin{array}{l}\text { Herpesvirus } \\
\text { skin infection }\end{array}$ & $\begin{array}{l}\text { Criterion } 1 \\
\text { and } 2\end{array}$ & $\begin{array}{l}\text { 1. Vesicular rash } \\
\text { 2. Doctor or laboratory } \\
\text { confirmation }\end{array}$ \\
\hline$E$ & $\begin{array}{l}\text { Oral } \\
\text { candidiasis }\end{array}$ & $\begin{array}{l}\text { Criterion } 1 \\
\text { and } 2\end{array}$ & $\begin{array}{l}\text { 1. Presence of raised white } \\
\text { patches or plaques in } \\
\text { mouth } \\
\text { 2. Doctor or dental provider } \\
\text { confirmation }\end{array}$ \\
\hline $\mathrm{F}$ & Scabies & $\begin{array}{l}\text { Criterion } 1 \\
\text { and } 2\end{array}$ & $\begin{array}{l}\text { 1. Maculopapular and/or } \\
\text { itching rash } \\
\text { 2. At least one sub-criteria } \\
\text { - Doctor or laboratory } \\
\text { confirmation } \\
\text { - Linkage to a } \\
\text { laboratory-confirmed } \\
\text { case of scabies }\end{array}$ \\
\hline
\end{tabular}

${ }^{a}$ Constitutional criteria include fever, leucocytosis, acute change in mental status from baseline and acute functional decline.

(expected $v s$. observed number of zeroes, $P=0.39$ ). Therefore, a negative binomial distribution was used.

Mixed-effects negative binomial modelling was performed by inclusion of patient (age, sex, known allergies, hospitalisation in last 30 days) and prescription-level covariates (antimicrobial type, indication specification, frequency specification, mode (written or phone), indication documentation, review/stop date recorded and prophylactic or treatment) at level 1 variables. Each participating $\mathrm{ACH}$ was added to level 2 as a random intercept to account for intra-facility variability. Starting with a maximal model containing all relevant covariates, model selection was performed using likelihood ratio tests. Model fit was assessed using residual plots. All analyses were conducted in the R programming language (Version 3.3.2). 
Table 2. Prevalence of antimicrobial prescribing for skin, soft tissue and mucosal clinical indications and proportion of confirmed infections

\begin{tabular}{|c|c|c|c|c|}
\hline \multirow[b]{2}{*}{$\begin{array}{l}\text { Clinical indication for commencing } \\
\text { antimicrobial }\end{array}$} & \multirow[b]{2}{*}{$\begin{array}{l}\text { Residents with prescription } \\
\text { prevalence (\%) ( } n=12307 \text { residents) }\end{array}$} & \multicolumn{3}{|c|}{ Residents with prescriptions that the start date was $<6$ months } \\
\hline & & $\begin{array}{c}\text { Total } \\
\text { number }\end{array}$ & $\begin{array}{l}\text { At least one infection } \\
\text { sign }+ \text { /or symptom (\%) }\end{array}$ & $\begin{array}{c}\text { McGeer et al } \\
\text { confirmed infection } \\
(\%)\end{array}$ \\
\hline Cellulitis, soft tissue or wound infection & $130(1.06)$ & 121 & $82(67.77)$ & $48(39.67)$ \\
\hline Fungal skin infection & $60(0.49)$ & 41 & $20(48.78)$ & $9(21.95)$ \\
\hline Oral candidiasis & $18(0.15)$ & 16 & $8(50.00)$ & $5(31.25)$ \\
\hline Herpes simplex or zoster & $3(0.02)$ & 3 & $2(66.67)$ & $2(66.67)$ \\
\hline Scabies & $1(0.01)$ & 1 & $0(0.00)$ & $0(0.00)$ \\
\hline Other & $210(1.71)$ & 95 & - & - \\
\hline
\end{tabular}

${ }^{a}$ Some residents prescribed antimicrobial therapy for $>1$ clinical indication.
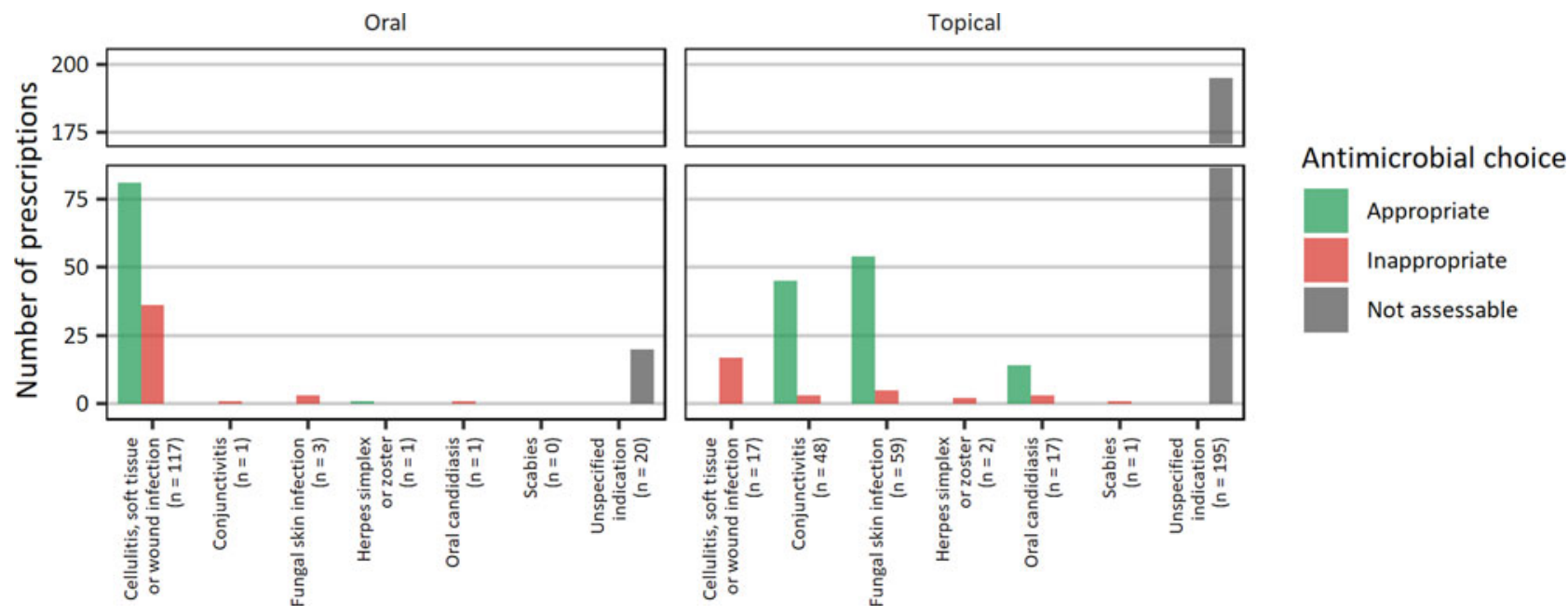

Fig. 1. Appropriateness of antimicrobial choice by skin indications.

\section{Ethics}

The study was reviewed and approved by the Melbourne Health Human Research Ethics committee as a Quality Assurance/ Negligible Risk Research project (QA 201 3066).

\section{Results}

Of the 292 participating aged care facilities, $67.8 \%$ were located in Victoria and $68.8 \%$ were operated by the Victorian State Government. Of the total 12307 residents audited, 67.0\% were female and the median age was 87.3 years (interquartile range (IQR): 80.7-92.0). A total of 1087 residents were prescribed an antimicrobial agent (8.8\%), 452 specifically for a SSTI clinical indication $(3.7 \%)$.

Four hundred and eighty-four antimicrobials were prescribed for a SSTI clinical indication. These antimicrobials were mostly administered topically $(70.0 \%)$ or orally $(29.6 \%)$. About two-thirds (65.7\%) had a known start date that was $<6$ months prior to the survey day - the median duration for these prescriptions was 7.0 days (IQR: 3.5-29.0) up to the survey day.

The most frequently reported clinical indications among residents were cellulitis, soft tissue or wound infection $(n=130)$, followed by fungal skin infection $(n=60)$, conjunctivitis $(n=49)$ and oral candidiasis $(n=18)$. Herpes simplex or zoster infections were reported in three instances and scabies in one instance. Table 2 summarises the prevalence of SSTI indications.

Where an antimicrobial agent was prescribed for an SSTI clinical indication and the known start date was $<6$ months prior to the survey day, a confirmed infection was infrequently documented $(29.0 \%)$. For antimicrobial prescriptions for conjunctivitis, infections confirmed by McGeer et al. criteria were present in $73.0 \%$; for cellulitis, soft tissue or wound infections, infection confirmed by McGeer et al. criteria was present in $40.0 \%$ (Table 2).

For cellulitis, soft tissue and wound infections, cephalexin and flucloxacillin were prescribed most frequently $(n=54$ (40.0\%) and 18 (13.3\%), respectively). For fungal skin infection, clotrimazole and miconazole were most frequently prescribed $(n=37 \quad(59.7 \%)$ and $14 \quad(22.6 \%)$, respectively). Topical 
chloramphenicol was the most frequently prescribed agent for conjunctivitis $(n=45(90.0 \%))$. Overall, clotrimazole was the most frequently prescribed agent $(39.6 \%)$, usually for unspecified clinical indications $(69.3 \%)$.

Where a specific clinical indication for prescribing oral or topical antimicrobial agents was known, $73.0 \%$ were aligned with national recommendations for antimicrobial prescribing. For cellulitis, soft tissue or wound infections, fungal skin infections, conjunctivitis and oral candidiasis, antimicrobial choice and route was appropriate in $60.0 \%, 87.1 \%, 91.8 \%$ and $77.8 \%$, respectively (Fig. 1). For cellulitis, soft tissue or wound infections, where selection of an agent was assessed as inappropriate, doxycycline $(n=8)$ and trimethoprim/sulfamethoxazole $(n=6)$ were most frequently prescribed. For 215 prescriptions, specific indications were not known, and appropriateness of agent selection was unable to be determined.

Duration of prescribing (in days) was significantly associated with use of an agent for prophylaxis (rate ratio (RR) 1.63, 95\% confidence interval $(95 \% \mathrm{CI}) 1.08-2.52)$, PRN (pro re nata or as required) orders (RR 2.10, 95\% CI 1.42-3.11) and prescription of a topical agent (RR 1.47, 95\% CI 1.08-2.02). Documentation of a review or stop date was associated with reduced duration of prescribing (RR 0.33, 95\% CI 0.25-0.43). Results of regression modelling are summarised in Table 3 . Intra-facility variability accounted for $53.5 \%$ (95\% CI 53.3-53.6\%) of all variability in duration of prescribing.

\section{Discussion}

Our study has provided a detailed evaluation of prescribing patterns for SSTIs in Australian aged care residents. We identified topical antifungal therapy to be the most frequently prescribed agent, and $\beta$-lactam agents to be most frequently prescribed oral agents for skin soft tissue and wound infections. A number of clinical practices were identified to be associated with longer duration of prescribing, including use of an agent for prophylaxis, PRN orders and prescription of topical agents.

Evaluation of the quality of prescribing included comparison of antimicrobial choice and route with national prescribing guidelines, and analysis of factors contributing significantly to prolonged prescriptions. We observed the majority (73.0\%) of targeted prescribing to be in accordance with national guidelines for antimicrobial therapy. Similarly, a European study of nursing homes found $76 \%$ of antibiotics prescribed for SSTIs were compliant with national guidelines [11]. However, a large proportion of prescribed agents were for unspecified clinical indications, meaning that appropriateness of antimicrobial agents could not be assessed.

We identified duration of prescribing of antimicrobial agents to be significantly associated with use of an agent for prophylaxis, PRN orders and prescription of a topical agent. This is consistent with international clinical observed practice, whereby prophylaxis may be commenced, but the duration unknown or undefined [12]. While PRN orders are likely to be applied to topical (rather than oral) antimicrobial therapies, it is conceivable that these would be less likely to be reviewed by clinicians and ceased when no longer clinically indicated. Conversely, documentation of a review or stop date was associated with reduced duration of prescribing. This finding supports the beneficial role of improved documentation to reduce antimicrobial treatment courses, potentially reducing risks of developing antimicrobial resistance.

For the current study, prescribing practices were compared to national prescribing guidelines, and analysis of factors
Table 3. Factors associated with duration (in days) of antimicrobial prescribing in aged care residents $(n=317)^{\mathrm{a}}$

\begin{tabular}{|c|c|c|c|}
\hline & $n$ & $\begin{array}{l}\text { Rate } \\
\text { ratio }\end{array}$ & $95 \% \mathrm{Cl}$ \\
\hline \multicolumn{4}{|l|}{ Gender } \\
\hline Male & 105 & 1.09 & $0.84-1.42$ \\
\hline Female & 212 & Referent & \\
\hline \multicolumn{4}{|c|}{ Allergies to antimicrobial agent(s) } \\
\hline Not documented & 6 & 1.14 & $0.41-3.33$ \\
\hline Yes & 68 & 0.75 & $0.56-1.03$ \\
\hline No & 243 & Referent & \\
\hline \multicolumn{4}{|c|}{ Indication documented by clinician? } \\
\hline Yes & 273 & 0.75 & $0.52-1.08$ \\
\hline No & 44 & Referent & \\
\hline \multicolumn{4}{|c|}{$\begin{array}{l}\text { Specific indication observed by } \\
\text { surveyor? }\end{array}$} \\
\hline Yes & 222 & 0.99 & $0.73-1.33$ \\
\hline No & 95 & Referent & \\
\hline \multicolumn{4}{|c|}{ Agent administered as prophylactic? } \\
\hline Yes & 29 & 1.63 & $1.08-2.52$ \\
\hline No & 288 & Referent & \\
\hline \multicolumn{4}{|l|}{ Type of antimicrobial } \\
\hline Antibacterial & 189 & 0.73 & $0.54-0.98$ \\
\hline Antiviral/anti-parasitic & 4 & 1.17 & $0.44-3.83$ \\
\hline Antifungal & 124 & Referent & \\
\hline \multicolumn{4}{|l|}{ Route of administration } \\
\hline Topical & 174 & 1.47 & $1.08-2.02$ \\
\hline Non-topical & 143 & Referent & \\
\hline \multicolumn{4}{|c|}{ Frequency of administration } \\
\hline PRN (as required) & 41 & 2.10 & $1.42-3.11$ \\
\hline Specific & 276 & Referent & \\
\hline \multicolumn{4}{|c|}{ Review/stop date recorded? } \\
\hline Yes & 173 & 0.33 & $0.25-0.43$ \\
\hline No & 144 & Referent & \\
\hline
\end{tabular}

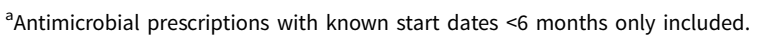

contributing significantly to prolonged prescriptions was performed. While these have not been specifically validated as measures of quality in aged care, we believe that comparison with a gold standard does enable benchmarking, and that risks for prolonged prescribing are an important consideration for potentially reducing unnecessary exposure to antimicrobial agents. Looking ahead, we acknowledge that an assessment tool for appropriateness is required, and that this should also incorporate understanding of allergies to antimicrobial agents, as well as local guidelines within aged care facilities.

Being reliant upon facility-level point-prevalence surveys, our study is limited by potential variability in case-mix of populations, varied quality of captured data and the chosen reporting period, which may all impact upon generalisability of results. Nonetheless, we believe this method to be advantageous for 
surveillance in aged care settings, given the relative ease of conducting point-prevalence surveys and minimal requirement for resources when compared to incidence surveys, which require more detailed data concerning admissions or discharges to a facility, continuous monitoring and therefore increased resources [13].

Our study is also limited by the representativeness of the surveyed population, mostly Victorian public aged care facilities. In Australia, aged care facilities are located in all states or territories, mainly New South Wales and are largely owned by not-for-profit or private organisations [1]. Further, the audit tool requires review of resident records to confirm the clinical indication and presence of signs and/or symptoms for infections. The quality of these data is dependent upon completeness of documentation. It is also unknown if the prevalence of residents prescribed at least one antimicrobial would have been lower if any PRN orders never administered had been excluded from the analyses.

In conclusion, we observed cellulitis, soft tissue or wound infections to be the most frequently reported SSTI in residents of Australian aged care facilities. While targeted antimicrobial prescribing is generally aligned with national recommendations, we observed a large proportion of prescribed antimicrobial agents to be for unspecified clinical indications. Interventions for improved antimicrobial prescribing should include review of prescribing of agents for prophylaxis, PRN orders and prescribing of topical agents. Methods to enhance clinician documentation of indications for antimicrobial therapy are required, and development of standardised tools for assessing appropriateness of antimicrobial agents in elderly populations would support these interventions.

Author ORCIDs. (D) N. J. Bennett, 0000-0003-0354-0881

Supplementary material. The supplementary material for this article can be found at https://doi.org/10.1017/S0950268819000128.

\section{References}

1. Commonwealth of Australia (2017) 2016-17 Report on the Operation of the Aged Care Act 1997. Commonwealth of Australia Canberra.

2. Garibaldi RA. Residential care and the elderly: the burden of infection. Journal of Hospital Infection 43(suppl), S9-18.

3. Kish TD, Chang MH and Fung HB (2010) Treatment of skin and soft tissue infections in the elderly: a review. American Journal of Geriatric Pharmacotherapy 8, 485-513.

4. Reddy M (2008) Skin and wound care: important considerations in the older adult. Advances in Skin and Wound Care 21, 424-436.

5. Gibbons JA, et al. (2017) Antimicrobial stewardship in the treatment of skin and soft tissue infections. American Journal Of Infection Control 45, 1203-1207.

6. Koch AM, et al. (2009) Severe consequences of healthcare-associated infections among residents of nursing homes: a cohort study. Journal of Hospital Infection 71, 269-274.

7. Bennett N, et al. (2018) Prevalence of infections and antimicrobial prescribing in Australian aged care facilities: evaluation of modifiable and nonmodifiable determinants. American Journal Of Infection Control 46, 1148-1153.

8. Stone ND, et al. (2012) Surveillance definitions of infections in long-term care facilities: revisiting the McGeer criteria. Infection Control And Hospital Epidemiology 33, 965-977.

9. Antibiotic Expert Group (2014) Therapeutic Guidelines: Antibiotic. Version 15. Melbourne Therapeutic Guidelines Limited.

10. Dermatology Expert Group (2015) Therapeutic Guidelines: Dermatology. Version 4. Melbourne Therapeutic Guidelines Limited.

11. Fagan M, et al. (2012) Antibiotic prescribing in nursing homes in an area with low prevalence of antibiotic resistance: compliance with national guidelines. Scandinavian Journal of Primary Health Care 30, 10-15.

12. European Centre for Disease Prevention and Control (2014) Point prevalence survey of healthcare-associated infections and antimicrobial use in European long-term care facilities. April-May 2013. Stockholm: ECDC.

13. Humphreys H and Smyth ET (2006) Prevalence surveys of healthcareassociated infections: what do they tell us, if anything? Clinical Microbiology and infection 12, 2-4. 